\title{
Datos de los autores
}

Carolina Fernández Cordero (Madrid, 1982). Licenciada en Filología Hispánica y Filología Clásica por la Universidad Autónoma de Madrid (años 2004 y 2009). En esa misma universidad obtuvo el Diploma de Estudios Avanzados (programa de doctorado Literaturas hispánicas y los géneros literarios en el contexto occidental) con el trabajo «El caballero encantado» de Galdós. Fantasía, mito y utopía (febrero 2008) y ahora se encuentra en su tercer año de beca predoctoral FPI de la Universidad Autónoma de Madrid, concedida para realizar la tesis doctoral Benito Pérez Galdós y la descomposición de la novela tradicional, dirigida por el profesor Julio Rodríguez Puértolas. Durante estos años de período formativo ha disfrutado de estancias en la Universidad de Las Palmas de Gran Canaria (2007), Mount Holyoke College, en Massachussets (2012) y la Universidad de La Habana (2013). Fernández Cordero ha publicado artículos y leído comunicaciones en diferentes congresos sobre Benito Pérez Galdós, el socialismo romántico, la cultura de la I y II República, la literatura posfranquista, y anteriormente, sobre el Siglo de Oro. Además ha trabajado en proyectos de investigación relacionados con el Siglo de Oro (Seminario Edad de Oro-Biblioteca Nacional, 2004-2008) y la literatura del exilio (Grupo GEXEL de la Universidad Autónoma de Barcelona), y en el proyecto «Catalogación del fondo manuscritos de la Biblioteca Nacional de España» (convenio FUAM-BNE 2008-2010).

José María Izquierdo (Valencia, 1954) es doctor (1993) por la Universidad de Valencia, España. Actualmente es bibliotecario de investigación y responsable del área de lenguas románicas de la Biblioteca de Humanidades y Ciencias sociales de la Universidad de Oslo (http://www.ub.uio.no/fag/sprak-litteratur/romansk/), ha sido, y lo es actualmente de forma esporádica, profesor de literatura española en el Departamento de literatura, estudios de zona y lenguas europeas (antiguo de Lenguas Clásicas y Románicas) de la misma universidad e imparte cursos de formación del profesorado de ELE en Noruega en relación con el uso de las TICs en la docencia. Su área de investigación se centra en la literatura española -campo en el que ha publicado numerosos artículosy en el uso de las TICs en la enseñanza. Izquierdo preside tanto la Asociación Noruega de Profesores de Español - ANPE (http://www.anpenorge.no/wordpress/), como la Federación Internacio- 
nal de Asociaciones de Profesores de Español - FIAPE (http://www.fiape.org) y es miembro fundador de la Asociación de Estudios de Manuel Vázquez Montalbán de la que es su secretario. Más información en: http://www.enmitg.com/wordpress/?page_id=4. Su dirección electrónica es: p.j.m.izquierdo@ub.uio.no

Stewart King es profesor titular de estudios españoles y catalanes, y jefe del Departamento de Estudios Españoles y Latinoamericanos en la Monash University, Australia. Es autor de Escribir la catalanidad. Lengua e identidades culturales en la narrativa contemporánea de Cataluña (Tamesis, 2005) y editor de las colecciones La cultura catalana de expresión castellana (Reichenberger, 2005) y The Space of Culture (University of Delaware Press, 2004). Ha publicado extensivamente sobre la novela negra y en la actualidad está terminando un estudio monográfico sobre el tema de la identidad cultural y nacional en la novela negra de España.

Àlex Martín Escribà ha trabajado en las universidades de La Habana y Grenoble, y actualmente es profesor de Filología Catalana en la Universidad de Salamanca. Sus investigaciones se centran en el género negro, tema de sus ensayos Catalana i criminal (2006) y La cua de Palla: retrat en groc i negre (2012). Es, asimismo, co-director del congreso de Novela y Cine Negro de la Universidad de Salamanca y autor de numerosos artículos de investigación y de crítica literaria. También ha sido editor de varias compilaciones de ensayos relacionados con el género negro, así como de las antologías de cuentos La lista negra. Nuevas voces del policial español (2010), Crims.Cat (2011), Sospechosos habituales. Tras la pista de la nueva novela negra española (2012). Es director de la colección Crims.Cat de la editorial Al Revés, especializada en novela negra.

Rosa María Rodríguez Abella es investigadora de Lengua española en la Facultad de Lenguas y Literaturas Extranjeras de la Universidad de Verona. Sus publicaciones se centran en la enseñanza del español como lengua extranjera (Escribir y algo más... De la comprensión oral y escrita a la expresión oral y escrita, Paravia, 1999), las lenguas de especialidad («La lengua de la promoción turística institucional. Análisis del portal www.spain.info» en PASOS, vol. N. 4, 2012) y la traducción de los referentes culturales («Viaje al universo Carvalho. Los pájaros de Bang- 
kok: referencias culturales y traducción» en Viaggiare con la parola. p. 165-182, FrancoAngeli, 2010).

Javier Sánchez Zapatero es profesor de Teoría de la Literatura y Literatura Comparada de la Universidad de Salamanca, institución en la que co-dirige el Congreso de Novela y Cine Negro y forma parte del GELYC (Grupo de Estudios de Literatura y Cine). Crítico literario en diversos medios de comunicación, es autor de numerosos artículos científicos en monografías y revistas especializadas, y del ensayo Escribir el horror. Literatura y campos de concentración (2010). Además, ha sido editor de varias compilaciones de ensayos relacionados con el género negro, así como de las antologías de cuentos La lista negra. Nuevas voces del policial español (2009) y Sospechosos habituales. Tras la pista de la nueva novela negra española (2012). Actualmente, sus líneas de investigación se centran en la narrativa y el cine policiacos, y en la literatura del exilio republicano.

José V. Saval se licenció en Ciencias de la Información (Periodismo) por la Universidad Autónoma de Barcelona y se doctoró en Filología española en la University of Virginia. Ha publicado los libros Carlos Barral, entre el esteticismo y la reivindicación, La ciudad de los prodigios, de Eduardo Mendoza, y Manuel Vázquez Montalbán: el triunfo de un luchador incansable. También ha editado los volúmenes La verdad sobre el caso Mendoza y Nuevas aportaciones a los estudios teatrales. Ha publicado artículos sobre diversos autores como Manuel Vázquez Montalbán, José Sanchis Sinisterra, Antonio Buero Vallejo, Dionisio Ridruejo, Javier Cercas y Mariano José de Larra, así como sobre los Novísimos y la influencia del Boom latinoamericano en la peninsula ibérica. Ha impartido conferencias en Australia, Colombia, España, Estados Unidos, Francia, Irlanda, Italia, Nueva Zelanda, Portugal y Venezuela. José Saval ha sido además presidente de la "Anglo-Catalan Society" y del "Scottish-Catalan Centre". Es en la actualidad jefe del departamento de "Hispanic Studies en la University of Edinburgh", así como miembro fundador de la "Asociacion internacional Manuel Vázquez Montalbán”. 